\title{
South Africa's rural mental health human resource crisis: a situation analysis and call for innovative task-shifting
}

\author{
JOHANNES H. DE KOCKA-F, BASIL J. PILLAYA, D-F \\ Department of Behavioural Medicine, University of KwaZulu-Natal, Durban, South Africa
}

A - Study Design, B - Data Collection, C - Statistical Analysis, D - Data Interpretation, E - Manuscript Preparation, F - Literature Search, G - Funds Collection

Summary Background. These data provide national estimates of the human resources and services available to address the mental health (MH) needs of over 17 million rural South Africans, reliant on public rural primary healthcare (PRPHC) facilities. With personnel regarded as the most valuable resource for service delivery within an MH system, this review's aim was to inform policy on bridging the mental illness treatment gap that is as high as $85 \%$ in low- and middle-income countries (LAMICS).

Objectives. The findings of three MH audits comprising 160 (98\%) of South Africa's (SA) PRPHC facilities are synthesised here to provide a situation analysis of SA's PRPHC MH human resources and services.

Material and methods. The review was based on the analysis of both primary and secondary data. Primary data were collected by interviewing the clinical heads of PRPHC facilities during the audits, while secondary data comprised a desk review.

Results. Results indicate that MH nurses (MHNs), clinical psychologists, $\mathrm{MH}$ medical doctors (MHMDs) and psychiatrists are practicing in PRPHC areas at rates of $0.68,0.47,0.37$ and 0.03 per 100000 population, respectively; $96 \%$ of facilities do not have psychiatrists employed, while $81 \%$ have no MHMDs, $64 \%$ do not have clinical psychologists, and $61 \%$ have no MHNs; $69 \%$ do not receive specialist MH outreach services, while $78 \%$ do not have $\mathrm{MH}$ multidisciplinary teams.

Conclusions. The MH workforce shortages in PRPHC areas are discussed in terms of the evidence based approaches of task-shifting and transdisciplinarity.

Key words: Africa, mental health, mental health services, primary health care, health resources, health services accessibility.

De Kock JH, Pillay BJ. South Africa's rural mental health human resource crisis: a situation analysis and call for innovative task-shifting.

Fam Med Prim Care Rev 2018; 20(2): 124-130, doi: https://doi.org/10.5114/fmpcr.2018.76454.

\section{Background}

With neuropsychiatric conditions contributing to approximately $13 \%$ of the global disease burden, it is not surprising that $\mathrm{MH}$ disorders are the third largest cause of disability in the world [1]. Mental Health (MH) disorders are responsible for $30 \%$ of disability-adjusted life-years (DA-LY's), the disability component of the burden of disease calculation $[2,3]$. With mental illness affecting a vast proportion of the global population, one could expect a proportionate quantity of $\mathrm{MH}$ practitioners available to address the afflicted population's needs. This is unfortunately not the case.

According to the World Health Organization (WHO), there is a global shortage of appropriately qualified medical healthcare professionals $[4,5]$. This is especially the case for low- and middle-income countries (LAMICs) [6-8].

Worldwide, the treatment gap for $\mathrm{MH}$ disorders is undeniable, with $85 \%$ of people in LAMICs and between $35 \%$ and $50 \%$ of people in high-income countries living with severe mental disorders receiving no medical treatment for their $\mathrm{MH}$ conditions $[2,3]$. Africa, as a continent, has the highest concentration of LAMICs, and the disease burden of MH disorders rests even more heavily here than in the rest of the world, accounting for $19 \%$ of all disability in this continent. More than $85 \%$ of people suffering from $\mathrm{MH}$ disorders on this continent do not receive medical treatment for their $\mathrm{MH}$ conditions [9].

The WHO further recognizes serious socio-economical risk factors in Africa, and proposes that the disease burden of mental disorders is likely to increase on this continent in the foreseeable future [3]. South Africa (SA), a middle income coun- try (MIC), shares the characteristics of its African counterparts when it comes to the $\mathrm{MH}$ workforce crisis and the socio-economical risk factors likely to increase mental illness [10].

Exacerbating the $\mathrm{MH}$ workforce crisis, $\mathrm{SA}$ and its African counterparts face a seriously unequal distribution of $\mathrm{MH}$ workers, with the majority these professionals practicing in urban and peri-urban settings [10]. SA is regarded as one as the most developed African countries, and is an economic powerhouse on the continent. Despite this, of its population of 52 million people, $53 \%$ live below the poverty line and approximately $40 \%$ live in rural areas [11-13]. It is in SA's public rural primary healthcare (PRPHC) areas where human resources for $\mathrm{MH}$ care are lowest $[14,15]$.

While WHO endorsed strategies such as task-shifting and transdisciplinarity have been developed to address primary healthcare (PHC)MH workforce shortages in LAMICs, SA's rural $\mathrm{MH}$ workforce remains unknown $[16,17]$. MH human resource approximations for rural SA have historically been based on estimates from district analyses [14, 18, 19], leaving considerable knowledge gaps. This paper therefore asks the question: What is SA's rural MH workforce?

\section{Objectives}

This situation analysis, a summary of three $\mathrm{MH}$ human resource audits [20-22], attempts to assist policy makers in filling the knowledge gap by providing a national evaluation of the $\mathrm{MH}$ workforce and services available to the approximately $17 \mathrm{mil}-$ lion South Africans reliant on PRPHC health facilities. We discuss and explore the evidenced-based strategies of task-shifting and 
transdisciplinarity to support human resources for $\mathrm{MH}$, with the aim of informing policy development in rural areas.

\section{Material and methods}

\section{Identification of data sources for the situation analysis}

A comprehensive secondary data review revealed a dearth of available information regarding the human resources for mental healthcare (MHC) in SA's rural areas. This secondary data review comprised a literature review on both global and local studies on SA's MH human resources. International data were acquired from the World Health Organization's (WHO's) Mental Health Atlas (a comprehensive report covering 99.3\% of the world's population) and the WHO Global Burden of Disease Report. Local sources included policies and reports by government departments such as the Department of Health (DoH) and the Health Professions Council of South Africa, non-profit organizations such as the Health Systems Trust, as well as statistical data from the census, and national household survey data from Statistics South Africa [23]. Using PubMed, Medline and PsychInfo, and not restricting the search to date, language or publication status, peer-reviewed works on SA's MH human resources status were identified using validated search strategies [24]. The South African Medical Journal, the South African Journal of Psychiatry, and the South African Journal of Psychology were hand-searched. In an effort to avoid publication bias, the literature search extended beyond scientific databases to grey literature and unpublished academic dissertations. Reading through the reference lists of key articles guided the inclusion of unpublished articles, and assisted in identifying key authors on the subject. The identified authors were contacted personally to ensure the inclusion of all relevant unpublished works.

The primary data for this situation analysis, collected between 2014 and 2016, were collected by three audits of the $\mathrm{MH}$ resources and services of $\mathrm{MH}$ professionals (mental health nurses [20], medical prescribers [21] and clinical psychologists [22]) in PRPHC health facilities. The aim of these audits and the subsequent synthesis of the data was to fill the secondary data analysis gaps with the goal of providing a comprehensive integrated view of the current PRPHC MH workforce situation.

\section{Procedure for primary data collection}

The audits [20-22] were initiated by obtaining ethics approval (BE 416/13) from the University of KwaZulu-Natal (UKZN) Biomedical Research Ethics Committee (BREC). For each province a specific request to conduct research at their public institutions was completed, and gatekeeper permission was obtained. Worldwide, a major hurdle in rural health research is defining which areas are to be included as "rural" [25] and therefore evidence based strategies were used to ensure accuracy: to ensure inclusiveness, data purging and refinement was deemed necessary as the only secondary data available for public perusal on rural health facilities' classification [26] were almost a decade old. During the last decade, SA has seen several provincial legislature, boundary and name changes. Each participating provincial DoH's information management director was contacted to provide an updated list of public health facilities regarded as rural, as well as the approximate population that it serves. All participating provinces officially confirmed that the DoH's Human Resource Management Circular of 2004 [26] was used as the basis to define their health facilities as "rural", but minor changes were made to the list, bringing the total number of health facilities included in the audits from the original 175 to an updated 163 .

Provincial district managers were contacted via telephone and e-mail to request them to provide the researchers with the names and contact details of chief executive officers (CEOs) and medical managers in the health facilities. CEOs have executive authority at health institutions and are required to personally approve the employment of health professionals at the facility where they are residing. Medical managers are medical doctors that manage all medical and allied health personnel at their institutions. The secondary data examination suggested that medical managers and CEOs should be included as key DoH stakeholders for the audit interviews as these professionals were judged to be in the best position to provide information about the $\mathrm{MH}$ human resources and services at their health facilities.

After obtaining informed consent, the medical managers/ /CEOs that agreed to participate in the audits were interviewed telephonically using a structured questionnaire developed by reviewing the WHO's audit tools [27] for situation analyses, as well as the DoH's strategic planning for $\mathrm{MH}$ resources [28]. The audits were constructed to obtain information about the human resources and services of a) Mental Health Nurses [20], b) clinical psychologists [22], and c) medical prescribers [21] (psychiatrists and medical officers dedicated to MHC). Where participants requested a written version of the questionnaire, an electronic version was sent to them via e-mail. In exceptional cases where facilities did not have CEOs or medical managers available for the interviews, nursing services managers (NSM) provided the institutions' information.

\section{Data analysis and presentation}

The telephonic interviews with the medical managers/CEOs were digitally recorded and transcribed. The electronic questionnaires were transferred from the FluidSurveys' encrypted domain to a Microsoft Excel Spreadsheet. The data from the telephonic and electronic questionnaires were combined and analysed using IBM's Statistical Software Package: SPSS.

\section{Results}

\section{Mental health human resources and rural population}

One hundred and sixty out of the 163 (98.3\%) South African PRPHC health facilities participated in the three audits [20-22 ]. One hundred and thirty-eight (86.3\%) medical managers, $20(12.5 \%)$ CEOs and two NSMs (1.3\%) provided the data for their institutions. The rural South African population reliant on PRPHC institutions was estimated at 17143872 people [11, 23]. These health centres employ a total of seven psychiatrists, 63 medical doctors dedicated to $\mathrm{MH}$ (MHMDs), 81 clinical psychologists [22] and $116 \mathrm{MH}$ nurses (MHNs) [20] at rates per 100000 population of $0.03,0.37,0.47$ and 0.68 , respectively (Table 1 ).

\section{Human resource distribution within PRPHC areas}

Table 2 represents the distribution of $\mathrm{MHC}$ professionals per province and indicates that $96.9 \%$ of the PRPHC healthcare facilities do not employ psychiatrists. The seven psychiatrists that are employed are concentrated in five facilities and available to only four of SA's provinces. The MHMDs in PRPHC areas are employed at 30 facilities, leaving $130(81.3 \%)$ institutions without medical prescribers dedicated to MHC. Clinical psychologists are employed at 57 (35.7\%) institutions [22] while MHNs are employed at 62 (38.8\%) of the PRPHC health facilities [20].

\section{MHC supplementary and out-reach services}

Of the 160 PRPHC facilities, 36 (22.5\%) had functional MHC multidisciplinary teams (MDTs). Excluding the $63 \mathrm{MHMDs}$ dedicated to provide MHC services at their institutions, a further 
three facilities (1.9\%) employ general (non-specialist) medical doctors (GMDs) with a weekly session dedicated to MHC, five facilities (3.1\%) employ GMDs with bi-weekly dedicated MHC sessions, while in four facilities (2.5\%) GMDs have three MHC sessions per week. Clinical psychologists provide outreach sessions to $26(16.3 \%)$ facilities, monthly, and to $13(8.1 \%)$ facilities on a bi-monthly basis [22]. With regard to specialist medical prescriber outreach services, $49(30.6 \%)$ facilities receive monthly psychiatrist visits, with 12 (7.5\%) facilities receiving bimonthly visits. A total of 99 (61.9\%) PRPHC health facilities do not receive psychiatrist outreach sessions. Table 3 provides an overview of the supplementary and outreach MHC services at PRPHC institutions. Table 4 depicts SA's MH workforce compared to that of other high MICs according to the World Bank income group classification [1].

\section{Future employment of MHC specialists in PRPHC facilities}

With psychiatrists and clinical psychologists regarded as the $\mathrm{MH}$ specialists employable in the DoH's public health sector, Table 5 indicates that 58 PRPHC facilities (36.3\%) confirmed clinical psychologists [22] and 9 facilities (5.6\%) confirmed psychiatrists as specialists in their future staff establishment plans.

\section{Human resource production}

There appears to be a discrepancy in the numbers of prescribing and non-prescribing $\mathrm{MH}$ specialists trained with clinical psychologists trained at more than four times the rate of psychiatrists and MHNs over the last decade (Table 6).

\begin{tabular}{|c|c|c|c|c|c|c|c|c|c|c|c|c|}
\hline & \multicolumn{2}{|c|}{$\begin{array}{l}\text { Rural population reliant } \\
\text { on PRPHC health facilities }\end{array}$} & \multicolumn{2}{|c|}{$\begin{array}{l}\text { Clinical } \\
\text { psychologists [22] }\end{array}$} & \multicolumn{2}{|c|}{ MHMDs [21] } & \multicolumn{2}{|c|}{ MHNs [20] } & \multicolumn{2}{|c|}{ Psychiatrists [21] } & \multicolumn{2}{|c|}{$\begin{array}{l}\text { Total MHC } \\
\text { Providers }\end{array}$} \\
\hline & Population & Facilities $(n)$ & $n$ & Rate & $n$ & Rate & $n$ & Rate & $n$ & Rate & $n$ & Rate \\
\hline EC & 3333810 & 31 & 0 & 0 & 10 & 0.3 & 13 & 0.39 & 0 & 0 & 23 & 0.69 \\
\hline FS & 465925 & 7 & 8 & 1.07 & 2 & 0.43 & 3 & 0.64 & 1 & 0.21 & 14 & 3.0 \\
\hline KZN & 4581901 & 34 & 11 & 0.24 & 6 & 0.13 & 27 & 0.59 & 1 & 0.02 & 45 & 0.98 \\
\hline LIM & 4105933 & 36 & 41 & 1.0 & 24 & 0.58 & 48 & 1.17 & 4 & 0.07 & 116 & 2.83 \\
\hline MPU & 1621686 & 17 & 11 & 0.68 & 13 & 0.8 & 9 & 0.55 & 0 & 0 & 33 & 2.03 \\
\hline NC & 173248 & 10 & 0 & 0 & 0 & 0 & 0 & 0 & 0 & 0 & 0 & 0 \\
\hline NW & 2063721 & 14 & 5 & 0.24 & 8 & 0.39 & 8 & 0.39 & 1 & 0.05 & 22 & 1.07 \\
\hline WC & 797648 & 11 & 5 & 1.0 & 0 & 0 & 8 & 1.0 & 0 & 0 & 13 & 1.63 \\
\hline Total & 17143872 & 160 & 81 & 0.47 & 63 & 0.37 & 116 & 0.68 & 7 & 0.03 & 266 & 1.55 \\
\hline
\end{tabular}

EC - Eastern Cape; FS - Free State, KZN - Kwazulu-Natal; LIM - Limpopo; MPU - Mpumalanga, NC - Northern Cape; NW - North West; WC - Western Cape; MHMD - Mental Health Medical Doctor (not specialized in psychiatry, but dedicated to Mental Health); MHN - Mental Health Nurse; * The rural population for each province making use of the public health sector was obtained by calculating the health centres included in the audit' population, as well as their affiliated satellite clinics' population.

\begin{tabular}{|c|c|c|c|c|c|c|c|c|c|c|c|c|c|c|c|c|c|c|}
\hline & \multicolumn{2}{|l|}{ EC } & \multicolumn{2}{|l|}{ FS } & \multicolumn{2}{|c|}{ KZN } & \multicolumn{2}{|c|}{ LIM } & \multicolumn{2}{|c|}{ MPU } & \multicolumn{2}{|l|}{ NC } & \multicolumn{2}{|c|}{ NW } & \multicolumn{2}{|c|}{ WC } & \multicolumn{2}{|c|}{ Total } \\
\hline & $n$ & $\%$ & $n$ & $\%$ & $n$ & $\%$ & $n$ & $\%$ & $n$ & $\%$ & $n$ & $\%$ & $n$ & $\%$ & $n$ & $\%$ & $n$ & $\%$ \\
\hline \multicolumn{19}{|c|}{ Clinical psychologists [22] } \\
\hline None & 31 & 100 & 3 & 42.8 & 23 & 67.6 & 11 & 30.6 & 9 & 52.9 & 10 & 100 & 9 & 64.2 & 7 & 63.6 & 103 & 64.4 \\
\hline One & 0 & 0 & 3 & 42.8 & 10 & 29.5 & 11 & 30.6 & 6 & 35.2 & 0 & 0 & 5 & 35.7 & 4 & 36.4 & 39 & 24.4 \\
\hline Two & 0 & 0 & 1 & 14.3 & 1 & 2.9 & 11 & 30.6 & 1 & 5.9 & 0 & 0 & 0 & 0 & 0 & 0 & 14 & 8.8 \\
\hline Three & 0 & 0 & 0 & 0 & 0 & 0 & 3 & 8.3 & 1 & 5.9 & 0 & 0 & 0 & 0 & 0 & 0 & 4 & 2.5 \\
\hline \multicolumn{19}{|c|}{ Medical Doctors [21] dedicated to MHC } \\
\hline None & 26 & 83.9 & 5 & 71.4 & 32 & 94.1 & 23 & 63.9 & 13 & 76.4 & 10 & 100 & 10 & 71.4 & 11 & 100 & 130 & 81.3 \\
\hline One & 2 & 6.5 & 2 & 28.6 & 1 & 2.9 & 8 & 22.2 & 1 & 5.9 & 0 & 0 & 1 & 7.1 & 0 & 0 & 15 & 9.4 \\
\hline Two & 2 & 6.5 & 0 & 0 & 0 & 0 & 2 & 5.6 & 0 & 0 & 0 & 0 & 2 & 14.2 & 0 & 0 & 6 & 3.8 \\
\hline Three & 0 & 0 & 0 & 0 & 0 & 0 & 1 & 2.8 & 0 & 0 & 0 & 0 & 1 & 7.1 & 0 & 0 & 2 & 1.3 \\
\hline Four & 1 & 3.2 & 0 & 0 & 0 & 0 & 2 & 5.6 & 3 & 17.6 & 0 & 0 & 0 & 0 & 0 & 0 & 6 & 3.8 \\
\hline Five & 0 & 0 & 0 & 0 & 1 & 2.9 & 0 & 0 & 0 & 0 & 0 & 0 & 0 & 0 & 0 & 0 & 1 & 0.6 \\
\hline \multicolumn{19}{|c|}{ MHC Nurses [20] } \\
\hline None & 24 & 77.4 & 5 & 71.4 & 15 & 44.1 & 16 & 44.4 & 11 & 64.7 & 10 & 100 & 10 & 71.4 & 7 & 63.7 & 98 & 61.3 \\
\hline One & 3 & 9.7 & 1 & 14.3 & 15 & 44.1 & 5 & 13.9 & 5 & 29.4 & 0 & 0 & 2 & 14.2 & 2 & 18.2 & 33 & 20.6 \\
\hline Two & 3 & 9.7 & 1 & 14.3 & 3 & 8.8 & 6 & 16.7 & 0 & 0 & 0 & 0 & 1 & 7.1 & 1 & 9.1 & 15 & 9.4 \\
\hline Three & 0 & 0 & 0 & 0 & 0 & 0 & 2 & 5.6 & 0 & 0 & 0 & 0 & 0 & 0 & 0 & 0 & 2 & 1.3 \\
\hline Four & 1 & 3.2 & 0 & 0 & 0 & 0 & 7 & 19.4 & 1 & 5.9 & 0 & 0 & 1 & 7.1 & 1 & 9.1 & 11 & 6.9 \\
\hline Five & 0 & 0 & 0 & 0 & 1 & 2.9 & 0 & 0 & 0 & 0 & 0 & 0 & 0 & 0 & 0 & 0 & 1 & 0.6 \\
\hline \multicolumn{19}{|c|}{ Psychiatrists [21] } \\
\hline None & 31 & 100 & 6 & 85.7 & 33 & 97 & 33 & 91.6 & 17 & 100 & 10 & 100 & 13 & 92.8 & 11 & 100 & 154 & 96.2 \\
\hline One & 0 & 0 & 1 & \begin{tabular}{|l|l}
14.3 \\
\end{tabular} & 1 & 3 & 2 & 5.5 & 0 & 0 & 0 & 0 & 1 & 7.1 & 0 & 0 & 5 & 3.1 \\
\hline Two & 0 & 0 & 0 & 0 & 0 & 0 & 1 & 2.8 & 0 & 0 & 0 & 0 & 0 & 0 & 0 & 0 & 1 & 0.6 \\
\hline
\end{tabular}

EC - Eastern Cape; FS - Free State; KZN - Kwazulu-Natal; LIM - Limpopo; MPU - Mpumalanga; NC - Northern Cape; NW - North West; WC - Western Cape; MHC - Mental Healthcare. 


\begin{tabular}{|l|l|l|l|l|l|l|l|l|l|l|l|l|l|l|l|l|l|l|l|l|l|l|l|l|l|l|}
\hline Table 3. The supplementary and outreach MHC services received by PRPC institutions [21] \\
\hline \\
\hline
\end{tabular}

EC - Eastern Cape; FS - Free State; KZN - Kwazulu-Natal; LIM - Limpopo; MPU - Mpumalanga; NC - Northern Cape; NW - North West; WC - Western Cape; MHC - Mental Healthcare; MDT - Multidisciplinary Team; GMD - General Medical Doctor.

\begin{tabular}{|c|c|c|c|}
\hline \multicolumn{4}{|c|}{ MH Professionals per cadre per 100000 population across healthcare settings } \\
\hline & $\begin{array}{l}\text { High Middle-Income Country } \\
\text { Average }\end{array}$ & SA National Average & SA PRPHC \\
\hline Clinical Psychologists [22] & 1.47 & 2.6 & 0.47 \\
\hline MHMDs [21] & 0.87 & 0.43 & 0.37 \\
\hline MHNs [20] & 9.72 & 9.72 & 0.68 \\
\hline Psychiatrists [21] & 2.03 & 0.27 & 0.03 \\
\hline
\end{tabular}

MIC - Middle Income Country; MH - Mental Health; PRPHC - Public Rural Primary Healthcare; MHMD - MH Medical Doctor (not specialized in psychiatry, but dedicated to $\mathrm{MH}) ; \mathrm{MHN}-$ Mental Health Nurse.

\begin{tabular}{|c|c|c|c|c|c|c|c|c|c|c|c|c|c|c|c|c|c|c|}
\hline & \multicolumn{2}{|l|}{ EC } & \multicolumn{2}{|c|}{ FS } & \multicolumn{2}{|c|}{ KZN } & \multicolumn{2}{|c|}{ LIM } & \multicolumn{2}{|c|}{ MPU } & \multicolumn{2}{|c|}{ NC } & \multicolumn{2}{|c|}{ NW } & \multicolumn{2}{|c|}{ WC } & \multicolumn{2}{|c|}{ Total } \\
\hline & $n$ & $\%$ & $n$ & $\%$ & $n$ & $\%$ & $n$ & $\%$ & $n$ & $\%$ & $n$ & $\%$ & $n$ & $\%$ & $n$ & $\%$ & $n$ & $\%$ \\
\hline \multicolumn{19}{|l|}{ MH Specialists } \\
\hline None & 23 & 74.2 & 7 & 100 & 12 & 35.3 & 15 & 41.7 & 11 & 64.7 & 8 & 80 & 8 & 57.1 & 9 & 81.8 & 93 & 58.1 \\
\hline $\begin{array}{l}\text { Clinical psycholo- } \\
\text { gists [22] }\end{array}$ & 8 & 25.8 & 0 & 0 & 22 & 64.7 & 15 & 41.7 & 4 & 23.5 & 2 & 20 & 5 & 35.7 & 2 & 18.2 & 58 & 36.3 \\
\hline Psychiatrists [21] & 0 & 0 & 0 & 0 & 0 & 0 & 6 & 16.7 & 2 & 11.8 & 0 & 0 & 1 & 7.1 & 0 & 0 & 9 & 5.6 \\
\hline
\end{tabular}

EC - Eastern Cape; FS - Free State; KZN - Kwazulu-Natal; LIM - Limpopo; MPU - Mpumalanga; NC - Northern Cape; NW - North West; WC - Western Cape; MHC - Mental Healthcare; $\mathrm{MH}-$ Mental Health.

\begin{tabular}{|c|c|c|c|c|c|c|c|c|c|c|c|}
\hline & \multicolumn{10}{|l|}{ Year } & \multirow[t]{2}{*}{ Total } \\
\hline & 2005 & 2006 & 2007 & 2008 & 2009 & 2010 & 2011 & 2012 & 2013 & 2014 & \\
\hline \multicolumn{12}{|l|}{ MHC Professionals } \\
\hline Clinical psychologists [22] & 101 & 130 & 126 & 107 & 134 & 98 & 118 & 133 & 159 & 132 & 1238 \\
\hline MHNs [20] & UN & UN & 37 & 35 & 56 & 42 & 55 & 41 & 123 & UN & 389 \\
\hline Psychiatrists [21] & 26 & 31 & 24 & 41 & 28 & 32 & 25 & 19 & 15 & 32 & 273 \\
\hline
\end{tabular}

MHC - Mental Healthcare; PHS - Public Health Sector; MHN - Mental Health Nurse; UN - Information not available. 


\section{Discussion}

\section{A disproportionate $\mathrm{MH}$ human resource distribution}

Of SA's population of 52 million people, more than 44 million $(84.6 \%)$ are reliant on the public health sector (PHS) for their healthcare needs $[23,30]$. Within the PHS, approximately 17 million people $(32.7 \%$ of SA's total population and $38.6 \%$ of the PHS) are reliant on PRPHC health facilities. This study's findings suggest an uneven distribution of $\mathrm{MH}$ human resources within the PHS. Globally, nurses are the most representative category of MHC professionals [31]. While this is also the case for $\mathrm{SA}$, with this cadre practicing on a national level at a rate of 9.7 per 100000 population [1], this study suggests MHNs rates are at 0.68 in PRPHC settings. Non-specialist medical doctors working in $\mathrm{MHC}$ are nationally represented at a rate of 0.43 per 100000 population and at 0.37 at PRPHC level. There are 762 psychiatrists registered in SA [32], with 302 (39.6\%) practicing in the public sector [33] and only seven (0.9\%) in PRPHC areas. The official South African psychiatrist to 100000 population ratio is 0.27 on a national level $[1,2,4]$, while this situation analysis indicates that it is 0.03 in PRPHC areas. Of the 2786 clinical psychologists practicing in SA, 1213 (43.5\%) are working in the public sector at a national rate of 2.6 per 100,000 population [34] and at a rate of 0.47 in PRPHC areas [22]

\section{A $\mathrm{MH}$ prescribing human resource crisis}

SA, rated by the World Bank as a high-MIC, [1] compares poorly to its counterparts with regard to psychiatrists and medical doctors working in $\mathrm{MH}$ settings (Table 5) [31]. According to official WHO statistics [1], MHNs' representation appear to be on par with other high MICs. The MHN's audit of this situation analysis [20], however, suggests a much lower rate of this cadre practicing in the PHS' PRPHC areas. Clinical psychologists (non-prescribing $\mathrm{MH}$ care specialists) are practicing in SA's PHS at rates higher than that of other high-MICs [34]. Across all cadres, the high-MIC average rate of $\mathrm{MH}$ professionals is 29.1 per 100000 population. This situation analysis suggests that the total average across all MH professionals is 1.55 per 100000 population in SA's PRPHC areas. Table 5 depicts SA's MH workforce compared to that of other high MICs, according to the World Bank income group classification [1]

\section{Strategies for increasing Mental Health Human Resources}

\section{Human resource production}

While the scaling up of MHC services has been advocated not only as a service delivery strategy, but also as a human rights and development priority in LAMICs [10, 31, 35, 36], the $\mathrm{MH}$ treatment gap remains enormous $[6,9,36,37]$. The futility of relying solely on an increase of the number of $\mathrm{MH}$ professionals to close this treatment gap is well-documented [14, 15, 36]. SA has, since the advent of its democracy and the introduction of its PHC focused health system, been struggling to produce sufficient human resources to meet its population's MHC demands [10]. Table 6, depicting the training of MHC professionals in SA over the last decade, suggests that prescribing MHC professionals will remain at a significant shortage for the foreseeable future with only modest gains made in numbers trained [29, 32, 38]. The discrepancy in the numbers of prescribing and non-prescribing $\mathrm{MH}$ specialists trained provides the opportunity to investigate task-shifting and transdisciplinarity as alleviation strategies [22].

\section{Task-shifting and transdisciplinarity}

Task shifting can be defined as the delegating of tasks to either new or existing professionals with less, or more narrowly focused training [6]. In MHC, this approach has historically been adopted to expand the role of MHNs and MHMDs to take over tasks like prescribing psychiatric medications and managing cases from psychiatrists. Task shifting within MHC has been found to be practical, effective, safe and cost-cutting $[6,15,39,40]$. SA already has a policy in place to allow for MHMDs and non-medical prescribers like MHNs, trained in MHC, to take over prescribing and case management roles from psychiatrists at $\mathrm{PHC}$ level [1]. This situation analysis indicates, however, that the current human resources in PRPHC areas provide insufficient MHNs and MHMDs to whom these tasks can be shifted.

These findings necessitate the need to develop other MHC professionals' capacities to deliver more holistic treatment solutions and to whom MHC tasks could be shifted at PHC level. SA has historically been at the forefront of innovation and policy with regard to PHC [41], and its DoH has placed major recent emphasis on the re-engineering of $\mathrm{MHC}$ within this system [42, 43]. An example of such innovation was the establishment of new cadres of health professionals such as clinical associates within the PHC system. Clinical associates (a mid-level PHC health practitioner), for example, are allowed to prescribe limited psychotropic medications with some legal restrictions, even though they are not specialist trained in MHC. Clinical associates and medical students have also now started to receive practical training in rural and PHC settings [44], an approach advocated as having positive effects on healthcare students' opinions of later working in these settings [45].

While the creation of mid-level practitioners and rural studentships are steps towards scaling-up MHC human resources and services, SA's dire human resource shortages at PHC level requires an even more creative problem-solving approach. Transdisciplinarity, or the transcendence of traditional professional boundaries by integrating knowledge from other health disciplines into its practice $[46,47]$, is one such creative approach that can be followed.

The 2015 World Psychiatric Association's (WPA) Annual Congress, themed "Primary Care Mental Health: Innovation and Transdisciplinarity", focused on the integration of MHC into PHC. The need to review, adjust and adapt traditional roles of healthcare professionals in order to achieve this integration has since been highlighted as a strategy to meet rural, underserved PHC populations' MHC needs [48]. The WPA adopted the Bucharest Statement on Collaborative and Integrated Care, calling for the inclusion of collaborative and integrated $\mathrm{MHC}$ in the updated United Nations Sustainable Development Goals [49]. The support for integration, innovation and transdisciplinarity within $\mathrm{MHC}$ has been met with so much support that the Bucharest Statement gave rise to the MH Reform Act of August 2015 in the USA [50]. If a country with a much larger number of $\mathrm{MH}$ human resources than LAMICS [1] deems it necessary to consider innovative solutions, it is suggested that other LAMICs follow suit.

Applying a transdisciplinarity approach to the training of health practitioners can lead to the development of new cadres of health professionals. Applying this approach to the continuous professional development of established cadres of MHC practitioners has led to successful task shifting which has had promising results [42]. An example is transforming PHC family physicians into comprehensive MHC providers to whom tasks traditionally allocated to psychiatrists could successfully be shifted.

\section{Limitations of the study}

Even though 160 PRPHC health facilities (98\%) were included in the audits, the lack of definitive current provincial and national documentation on PRPHC facility classification may have led to some institutions being omitted. The unavailability of official recent PRPHC records also proposes that the population reliant on PRPHC facilities should be interpreted with caution. Even though this calculation was done by triangulating primary (as discussed in the Method section) and secondary sources [11, 
$12,23]$, the numbers should be regarded as a conservative approximation $[12,33]$.

\section{Conclusions}

The situation analysis conducted in this paper addresses the question regarding SA's rural MH human resources. It provides a synthesis of not only the national estimates of $\mathrm{MH}$ human resources in SA's PRPHC settings, but also of its services. The findings of this paper suggest dire shortages with a disproportionately low distribution of MHC professionals in rural PHC areas. These findings indicate that traditional scaling up strate- gies such as redistributing and training more MHC professionals alone would prove to be inadequate to meet the $\mathrm{MH}$ needs of the population reliant on PRPHC. Innovative strategies such as task-shifting have been implemented, but the severe $\mathrm{MH}$ workforce shortages at PHC level suggests insufficient MHC professionals to whom tasks can be shifted. In order for SA to make tangible in-roads into the $\mathrm{MH}$ human resource crisis at $\mathrm{PHC}$ level, it requires more $\mathrm{MHC}$ personnel to whom traditional tasks dedicated to psychiatry can be shifted. This could be achieved by using evidenced based transdisciplinarity principles in the training of both new cadres of $\mathrm{MHC}$ professionals and already established MHC professions.

Source of funding: This work was funded from the authors' own resources.

Conflicts of interest: The authors declare no conflicts of interest.

\section{References}

1. World Health Organization. Mental Health Atlas 2014. Geneva: WHO; 2015: 82.

2. World Health Organization. Access and use of psychotropic medicines. WHO Drug Information 2004; 18: 1-244.

3. World Health Organization. The global burden of mental disorders and the need for a comprehensive, coordinated response from health and social sectors at the country level. The 65th World Health Assembly. Geneva: WHO; 2012.

4. World Health Organization. WHO launches the World Health Statistics 2012. Euro Surveillance: Bulletin Européen Sur Les Maladies Transmissibles = European Communicable Disease Bulletin 2012; 17.

5. Shah AA, Beinecke RH. Global mental health needs, services, barriers, and challenges. Int J Ment Health 2009; 38: 14-29.

6. Bruckner TA, Scheffler RM, Shen G, et al. The mental health workforce gap in low- and middle-income countries: a needs-based approach. Bull World Health Organ 2011; 89: 184-94.

7. World Health Organization. Task shifting: rational redistribution of tasks among health workforce teams: global recommendations and guidelines. Geneva: WHO; 2008: 1-82.

8. Ezisi CN, Eze BI, Okoye O, et al. Challenges in horizontal integration of eye care services into the pre-existing rural primary care structure: an operations research perspective from Nigeria. Fam Med Prim Care Rev 2017; 19(4): 366-371.

9. World Health Organization. Mental Health Gap Action Programme. Special Focus: Launch of the Mental Health Action Plan $2013-2020$. Geneva: WHO; 2013.

10. Burns JK. The mental health gap in South Africa - a human rights issue. Equal Rights Rev 2011; 6: 99-113.

11. Kok P, Collinson M. Migration and urbanisation in South Africa. Pretoria: Statistics South Africa; 2006.

12. Lehohla P. Census 2011. Census in brief. Pretoria: Statistics South Africa; 2013: 105.

13. CIA. World Fact Book. South Africa. Washington (DC): Central Intelligence Agency; 2014.

14. Lund C, Petersen I, Kleintjes S, et al. Mental health services in South Africa: taking stock. Afr J Psychiatry 2012; 15: 402-405.

15. Petersen I, Lund C, Bhana A et al. A task shifting approach to primary mental health care for adults in South Africa: human resource requirements and costs for rural settings. Health Policy Plan 2012; 27(1): 42-51.

16. Thornicroft G, Alem A, Santos RA, et al. WPA guidance on steps, obstacles and mistakes to avoid in the implementation of community mental health care. World Psychiatry 2010; 9(2): 67-77.

17. Saxena S, Sharan P, Garrido M, et al. World Health Organization's mental health atlas 2005: implications for policy development. World Psychiatry 2006; 5(3): 179-184.

18. Petersen I, Bhana A, Campbell-Hall V, et al. Planning for district mental health services in South Africa: a situational analysis of a rural district site. Health Policy Plan 2009; 24(2): 140-150.

19. Hanlon C, Luitel NP, Kathree T, et al. Challenges and opportunities for implementing integrated mental health care: a district level situation analysis from five low- and middle-income countries. PLOS ONE 2014; 9(2): e88437, doi: 10.1371/journal.pone.0088437.

20. De Kock J, Pillay B. Mental health nurses in South Africa's public rural primary care settings: a human resource crisis. Rural Remote Health 2016; 16(3): 3865.

21. De Kock JH, Pillay BJ. A situation analysis of psychiatrists in South Africa's rural primary healthcare settings. Afr J Prim Health Care Fam Med 2017; 9(1): e1-e6, doi: 10.4102/phcfm.v9i1.1335.

22. De Kock JH, Pillay BJ. A situation analysis of clinical psychology services in South Africa's public rural primary care settings. $S$ Afr J Psychol 2016; 47(2): 260-270, doi: https://doi.org/10.1177/0081246316673243:0081246316673243.

23. Lehohla P. Use of health facilities and levels of selected health conditions in South Africa: findings from the general household survey, 2011. Pretoria: Statistics South Africa; 2013: 114.

24. Wilczynski NL, Haynes RB, Hedges T. Optimal search strategies for identifying mental health content in MEDLINE: an analytic survey. Ann Gen Psychiatry 2006; 5: 4, doi: 10.1186/1744-859X-5-4.

25. Petrovcic R. Defining rural, remote and isolated practices: the example of Slovenia. Fam Med Prim Care Rev 2016; 18(3): $391-393$.

26. Department of Health. Human Resource Management Circular 87 of 2004. In: South African Department of Health, ed. Pretoria: Department of Health; 2004.

27. World Health Organization. Situation analysis and priority setting. National health policies, strategies and plans. Geneva: World Health Organization; 2015.

28. Department of Health. National Mental Health Policy Framework and Strategic Plan 2013-2020. Pretoria: National Department of Health; 2013.

29. Health Professions Council of South Africa (HPCSA). Registration Statistics for Psychiatry. Pretoria: HPCSA; 2013: 1-2.

30. Council for Medical Schemes. Public Sector Dependent Population. In: Council for Medical Schemes, ed. Medical Schemes 2013-2014: Council for Medical Schemes Annual Report 2013/14. Hatfield, Pretoria: Council for Medical Schemes; 2014.

31. Morris J, Lora A, McBain R, et al. Global mental health resources and services: a WHO survey of 184 countries. Public Health Rev 2012; 34(2): 1-19. 
32. Health Professions Council of South Africa (HPCSA). Output of clinical psychologists per year. Pretoria: HPCSA; 2015 : 3-4.

33. Human Resources for Health South Africa (HRHSA): Human Resources for Health Strategy for the Health Sector: 2012/13-2016/17. Johannesburg: South African Department of Health; 2012: 165-166.

34. Day C, Gray A. Health and related indicators. South African Health Review 2014; 1: 201-345.

35. Lund C, De Silva M, Plagerson S, et al. Poverty and mental disorders: breaking the cycle in low-income and middle-income countries. Lancet 2011; 378(9801): 1502-1514.

36. Lund C, Alem A, Schneider M, et al. Generating evidence to narrow the treatment gap for mental disorders in sub-Saharan Africa: rationale, overview and methods of AFFIRM. Epidemiol Psychiatr Sci 2015; 24(3): 233-240.

37. Patel V, Maj M, Flisher AJ, et al. Reducing the treatment gap for mental disorders: a WPA survey. World Psychiatry 2010; 9(3): 169-176.

38. Colleges of Medicine South Africa (CMSA). Psychiatrists qualifying per year. Johannesburg: CMSA; 2015:1-2.

39. Fulton BD, Scheffler RM, Sparkes SP, et al. Health workforce skill mix and task shifting in low income countries: a review of recent evidence. Hum Resour Health 2011; 9: 1-11.

40. Patel V. Global mental health: from science to action. Harv Rev Psychiatry 2012; 20(1): 6-12.

41. Kautzky K, Tollman S. A perspective on primary health care in South Africa. South African Health Review 2008; 20. Available from URL: https://pdfs.semanticscholar.org/23a9/9b4b771f0048313925193bfe4206f7d25bd7.pdf.

42. Motsoaledi AP. Speaking notes for the minister of health: Dr AP Motsoaledi at the national mental health summit. Johannesburg: South African Ministry of Health; 2012: 1-2. Available from URL: http://www.polity.org.za/article/sa-motsoaledi-address-by-the-minister-ofheallth-at-the-national-mental- health-summit-johannesburg-12042012-2012-04-12.

43. Department of Health. National Department of Health Strategic Plan 2010/11-2012/13. Pretoria: Department of Health; 2010.

44. Motsoaledi AP. Regulations defining the scope practice of clinical associates. Pretoria: South African Department of Health; 2014: 1-4.

45. Petrovcic R. Students' opinions on working in rural practice in Slovenia. Fam Med Prim Care Rev 2016; 18(4): 448-454.

46. Choi B, Pak A. Multidisciplinarity, interdisciplinarity and transdisciplinarity in health research, services, education and policy: 1 . Definitions, objectives, and evidence of effectiveness. Clin Invest Med 2006; 29(6): 351-364.

47. Soskolne C. Transdisciplinary approaches for public health. Epidemiology. Philadelphia: Lippincott Williams \& Wilkins; 2000: S122-S.

48. Wahlbeck K. Public mental health: the time is ripe for translation of evidence into practice. World Psychiatry 2015; 14(1): 36-42.

49. Bhugra D, Herman H, Kallivayalil R, et al. WPA Bucharest statement on collaborative and integrated care. Bucharest: World Psychiatric Association; 2015.

50. World Psychiatric Association (WPA). Mental health reform act: WPA Bucharest statement on collaborative and integrated care. Bucharest: WPA; 2015: 1-2.

Tables: 6

Figures: 0

References: 50

Received: 01.12.2017

Reviewed: 15.01 .2018

Accepted: 29.01.2018

Address for correspondence:

Johannes H. De Kock, PhD

Department of Behavioural Medicine

University of Kwa-Zulu-Natal

301 George Campbell Building, Howard College

Durban, KwaZulu-Natal, 4041

South Africa

Tel.: 0824977428

E-mail: jhdk.dekock@gmail.com 